8 - ORIGINAL ARTICLE

WOUND HEALING

\title{
Amniotic membrane as a biological dressing in infected wound healing in rabbits ${ }^{1}$
}

\author{
Ian Göedert Leite DuarteI, Ivana Duval-Araujo ${ }^{\text {II }}$
}

DOI: http://dx.doi.org/10.1590/S0102-86502014000500008

IMaster, Fellow PhD degree, Postgraduate Program in Surgery, Medical School, Federal University of Minas Gerais (UFMG), Belo Horizonte-MG, Brazil. Acquisition and interpretation of data, technical procedures, statistical analysis, manuscript writing, critical revision.

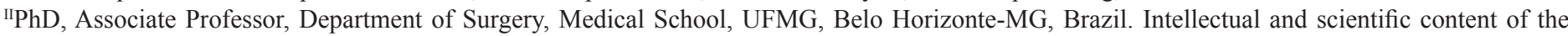
study, design the protocol, interpretation of data, manuscript writing, critical revision.

\section{ABSTRACT}

PURPOSE: To investigate amniotic membrane as a biological dressing in infected wound healing in rabbits.

METHODS: The use of preserved amniotic membranes (AMs) was examined using 15 rabbits with experimentally induced wound infections on their backs. Healing was histologically evaluated during different phases including inflammation, granulation, epithelialization, and fibroplasia. The animals were distributed into three groups for histological study at seven, 14, 21, and 28 days postwound induction. Group A did not receive treatment: the wound was left exposed and dry; Group B received a daily exposure treatment with collagenase; and Group C received one AM, which also remained exposed.

RESULTS: A marked reduction of the inflammatory phase was observed in Group $\mathrm{C}$ at 21 days, and the granulation phase of this healing increased at 14 days. Epithelialization was similar among the three groups, and fibroplasia was more pronounced in Group C at 14 days. Furthermore, gradual collagen organization also began for the animals in Group B at 14 days.

CONCLUSION: The amniotic membrane did not significantly alter the inflammation, epithelialization, or fibroplasia phases but did increase angiogenesis up to Day 14 compared with the dry dressing and collagenase treatments.

Key words: Biological Dressings. Granulation Tissue. Wound Healing. Rabbits. 


\section{Introduction}

Wounds can be defined as the recent or old discontinuity of any bodily soft tissues, with or without the loss of basic function. Infected wounds have a much longer tissue repair time and usually have associated complications ${ }^{1-4}$.

Wound healing is a complex event that involves reactions and interactions between cells and biochemical mediators that attempt to repair the injured area and begins immediately following an injury ${ }^{3-4}$. Several methods and dressings are available to enhance and accelerate the healing process. Amniotic membranes (AMs) have been used for this purpose. According to Fontenla et al. ${ }^{5}$, Ivanova published an article in 1890 regarding the transplant of fetal skin onto burn victims; in 1910, Davis announced his intention to inject fragments of the amniotic sac into open wounds. According to Schwanet al. ${ }^{6}$, the use of AM began with De Rotth in 1940 in ophthalmology, the specialty in which AM is currently most heavily researched. Studies have described its application in varicose ulcers ${ }^{7}$, burns $^{8}$, neovaginal reconstruction ${ }^{9}$, urinary bladder reconstruction ${ }^{10}$, nerve damage ${ }^{11}$, oral wounds ${ }^{12}$, skin trauma ${ }^{13}$, ocular injuries ${ }^{14}$, adhesion control, and peritoneal structure scarring ${ }^{15}$.

The clinical applicability of AM has become increasingly important due to their low antigenicity and antimicrobial action as well as their ability to decrease exudate and adhesions, accelerate epithelialization, reduce local pain, act as a substrate for the growth of tissues, and so on ${ }^{16-19}$. These properties suggest that AM could be used as a biological dressing, thereby providing an alternative for chronic wound treatment and benefitting certain phases of the healing process including inflammation, granulation, epithelialization, and fibroplasia. This study evaluated the efficacy of AM as a biological dressing in the infected wound healing of rabbits by histologically assessing the following phases of wound healing: a-inflammation, b-granulation, c-epithelialization, and d-fibroplasia.

\section{Methods}

The Ethics Committee for Animal Experimentation at the Federal University of Minas Gerais (UFMG) approved this study under Protocol No. 039/05.

A total of 15 adult male New Zealand rabbits were used (average weight $=2.706 \mathrm{~g}$ ). The rabbits were provided standard chow and water ad libitum during the entire experimentation period.

The animals were randomly divided into three groups of five rabbits. All animals received experimentally induced wound infections on their backs via the application of a solid gel containing
1.5 X $10^{5} \mathrm{CFU}$ of Staphylococcus epidermidis following general anesthesia. Care related to water intake was monitored for two hours, and food intake was monitored for eight hours.

Cleaning and debridement were performed five days post-wound induction. On Day 7, the wounds of the animals in Group A were cleaned with a $0.9 \%$ saline solution to remove biopsies, and the exposure and dry treatment without a dressing or daily cleaning began. The wounds of the animals in Group B were cleaned with a $0.9 \%$, saline solution to remove biopsies, and the collagenase exposure treatment began on Day 7 without a dressing, except for a layer of medication on the wound surface without daily cleanings. The AM dressing was applied following the cleaning and biopsy removal with $0.9 \%$ saline in Group C on Day 7. This dressing was removed from the refrigerator 30 minutes prior to use and rehydrated for 10 minutes in a $0.9 \%$ saline solution.

The AMs were separated from the paper and placed on the wounds with their stromal faces in contact with the open wound and fixed to intact skin with separated 5.0 mononylon sutures. The wounds were dried, and small air bubbles were removed. The membranes were not changed during the treatment period. Biopsies were taken from the three groups following the antisepsis on Days 14, 21, and 28.

The AMs were obtained from an adult rabbit during a cesarean section following a full-term pregnancy. The AMs were removed from nine pups, isolated from other fetal membranes, and washed in a sterile vessel containing a $0.9 \%$ saline solution until all coagulants were completely removed. The AMs were then immersed in $745 \mathrm{ml}$ of sterile buffer solution containing potassium phosphate monobasic $(6.8 \mathrm{mg} / \mathrm{ml})$, sodium hydroxide (1.39 mg/ml), penicillin G (1.000 IU/ml), and Amphotericin B (5 $\mathrm{mcg} / \mathrm{ml})$. Each membrane was spread on nitrocellulose filter paper with its stromal face in contact with the paper and immersed in sterile plastic vials containing $10 \mathrm{ml}$ of $98 \%$ glycerin and $1.5 \mathrm{ml}$ of the Ophthalmos ${ }^{\circledR}$ corneal conservation medium for storage. The $\mathrm{AM}$ were then refrigerated at $8^{\circ} \mathrm{C}$ until use or 36 days after being prepared and preserved.

The incisional wound biopsies were conducted in the upper right quadrant (Day 7), lower right quadrant (Day 14), lower left quadrant (Day 21), and upper left quadrant (Day 28) by removing a portion of the injured area and the underlying skin. The biopsied areas were sutured with simple 5.0-mononylon sutures. The tissue fragments were placed in vials containing $10 \%$ formalin, identified, stained with hematoxylin and eosin, and sent for histological examination. The following parameters were then examined: I - Angiogenesis and inflammatory cell infiltration, 
classified as absent, mild, moderate, or severe; II - cell types present in inflammatory infiltrate, i.e., mononuclear cells (macrophages, plasmocytes, and lymphocytes), polymorphonuclear leukocytes (neutrophils), and mixtures of the two; III - the presence of foreign-body giant cells reactions; and IV - the presence of fibrosis composed of young and old fibers, categorized as absent, mild, moderate, or severe.

All animals were sacrificed on Day 28 according to the euthanasia parameters recommended by DG XI of the Commission of European Communities.

Fisher's exact test for non-parametric samples was used to evaluate the qualitative microscopy findings for each time point between groups and the disease evolution from Day 7 to Day 28 within each group. The significance level was set at $5 \%$ for all analyses $(\mathrm{p} \leq 0.05)$.

\section{Results}

One animal in Group C was excluded from the study because it had an extensive area of necrosis at the lesion site and the surrounding area 24 hours after the AM was placed.

\section{Inflammatory infiltrate}

Four of the animals in Group A, five in Group B, and four in Group $\mathrm{C}$ had moderate/severe inflammatory infiltrates on Day 7 that did not significantly differ between groups and consisted mainly of mixed cells. One animal (20\%) in Group A $(p=0.006)$, four $(80 \%)$ in Group B, and four $(100 \%)$ in Group $\mathrm{C}$ had predominantly mononuclear cells on Day 14 . Only one animal from Groups B and one from Group C (20\% and 25\%, respectively) had predominantly mononuclear cells on Day 21; however, these cells were absent from Group A (N.S.). On Day 28, these cells were noted in one Group A animal and one Group B animal (20\% and 20\%, respectively); however, they were absent in Group C animals (N.S.; Table 1 and Figure 1).

TABLE 1 - Inflammatory infiltrate of infected wounds among rabbits: A, untreated (control); B, collagenase-treated (control); and C, treated with $\mathrm{AM}$ at $7,14,21$, and 28 days post-wound induction

\begin{tabular}{lccccccccc}
\hline & \multicolumn{1}{c}{ DAYS } \\
\cline { 2 - 9 } GROUPS & \multicolumn{1}{c}{7} & \multicolumn{1}{c}{14} & \multicolumn{2}{c}{21} & \multicolumn{2}{c}{28} \\
\cline { 2 - 9 } & $\mathrm{n}$ & $\%$ & $\mathrm{n}$ & $\%$ & $\mathrm{n}$ & $\%$ & $\mathrm{n}$ & $\%$ \\
\hline A (control) & 4 & 80 & $1 *$ & 20 & 0 & 0 & 1 & 20 \\
B (collagenase) & 5 & 100 & 4 & 80 & $1 \bullet$ & 20 & 1 & 20 \\
C (AM) & 4 & 100 & 4 & 100 & $1 \bullet$ & 25 & 0 & 0 \\
\hline
\end{tabular}

*p=0.006; $\bullet=0.01 ; \bullet p=0.002$

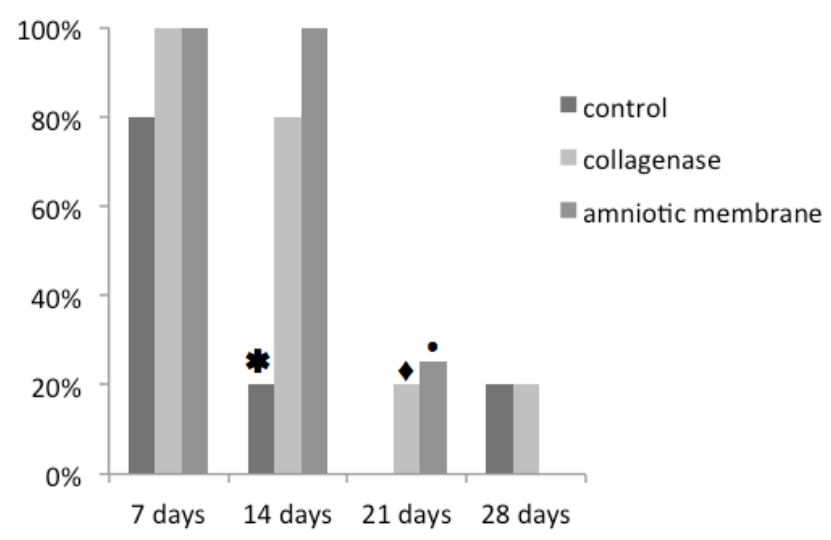

FIGURE 1 - The evolution of the inflammatory infiltrate in infected wounds among rabbits: A, untreated (control); B, collagenase treated; and $\mathbf{C}$, treated with $\mathrm{AM}$ at $7,14,21$, and 28 days post-wound induction $(* \mathrm{p}=0.006 \diamond \mathrm{p}=0.01 \cdot \mathrm{p}=0.002)$.

\section{Granulation}

On Day 7, the granulation tissue was moderate/severe in three of the Group A animals (60\%), one of the Group B animals (20\%), and none of the Group C animals. On Day 14, the granulation tissue was observed in one of the Group A animals (20\%), one of the Group B animals (20\%), and all of the Group C animals (100\%). Granulation tissue was not observed in any animal on Day 21, and none of the Group A and C animals had granulation tissue on Day 28; however, some granulation tissue was present in one of the Group B animals (20\%; Table 2 and Figure 2).

TABLE 2 - Tissue granulation of infected wounds among rabbits: A, untreated (control); B, collagenase-treated (control); and C, treated with $\mathrm{AM}$ at 7, 14, 21, and 28 days post-wound induction

\begin{tabular}{lcccccccc}
\hline \multirow{2}{*}{ GROUPS } & \multicolumn{8}{c}{ DAYS } \\
\cline { 2 - 10 } & \multicolumn{2}{c}{7} & \multicolumn{1}{c}{14} & \multicolumn{2}{c}{21} & \multicolumn{2}{c}{28} \\
\cline { 2 - 10 } & $\mathrm{n}$ & $\%$ & $\mathrm{n}$ & $\%$ & $\mathrm{n}$ & $\%$ & $\mathrm{n}$ & $\%$ \\
\hline A (control) & 3 & 60 & 1 & 20 & 0 & 0 & 0 & 0 \\
B (collagenase) & 1 & 20 & 1 & 20 & 0 & 0 & 1 & 20 \\
C (AM) & 0 & 0 & $4 \cdot$ & 100 & 0 & 0 & 0 & 0 \\
\hline
\end{tabular}

$\cdot \mathrm{p}=0.001$

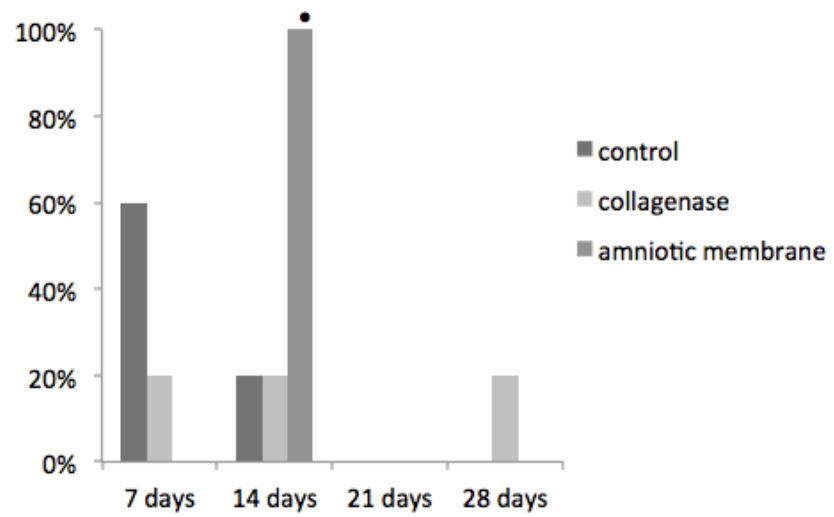

FIGURE 2 - The evolution of tissue granulation among infected wounds in rabbits: A, untreated (control); $\mathbf{B}$, collagenase treated; and $\mathbf{C}$, treated with $\mathrm{AM}$ at $7,14,21$, and 28 days post-wound induction. $(\cdot \mathrm{p}=0.001)$. 


\section{Epithelialization}

The wounds evolved similarly among the three groups on Day 7, when fibrin and exudate were the predominant indicators. On Day 14, there were Signs of epithelialization were observed in four (80\%) Group A wounds, three (60\%) Group B wounds $(\mathrm{p}=0.05)$, and no Group $\mathrm{C}$ wounds. On Day 21 , three $(60 \%)$, five $(100 \%)$, and two $(50 \%)$ of the wounds in Groups A, B, and $\mathrm{C}$, respectively, showed signs of re-epithelialization. Moreover, hyperplasia was present in the Group A and C animals; these groups were not significantly different. On Day 28, signs of reepithelialization were observed in two Group A animals (40\%), three Group B animals (60\%), and two (50\%) Group C animals. The evolutions of wound re-epithelialization in each individual group (assessed using the proliferation of basal layer during the various healing phases) were significantly different in the dry ( $p=$ $0.01)$ and collagenase $(p=0.05)$ control groups but not in the AM group ( $\mathrm{p}=0.08$, Table 3 and Figure 3 ).

TABLE 3 - Signs of infected wound re-epithelialization among rabbits: A, untreated (control); B, collagenase-treated (control); and C, treated with $\mathrm{AM}$ at 7, 14, 21, and 28 days post-wound induction

\begin{tabular}{lcccccccc}
\hline \multirow{2}{*}{ GROUPS } & \multicolumn{10}{c}{ DAYS } \\
\cline { 2 - 10 } & \multicolumn{2}{c}{7} & \multicolumn{1}{c}{14} & \multicolumn{2}{c}{21} & \multicolumn{2}{c}{28} \\
\cline { 2 - 10 } & $\mathrm{n}$ & $\%$ & $\mathrm{n}$ & $\%$ & $\mathrm{n}$ & $\%$ & $\mathrm{n}$ & $\%$ \\
\hline A (control) & 0 & 0 & $4 *$ & 80 & 3 & 60 & 2 & 40 \\
B (collagenase) & 0 & 0 & 3 & 60 & 5 & 100 & 3 & 60 \\
C (AM) & 0 & 0 & 0 & 0 & 2 & 50 & 2 & 50 \\
\hline
\end{tabular}

$$
* \mathrm{p}=0.05
$$

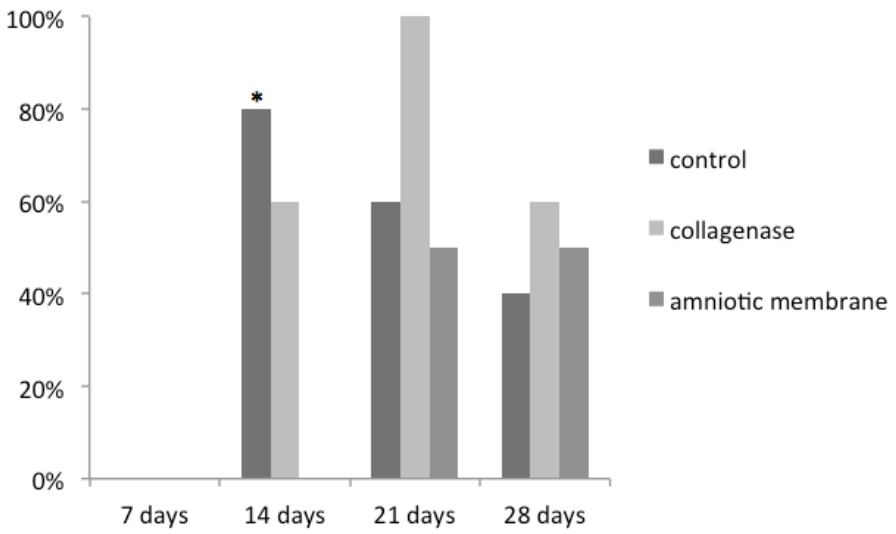

FIGURE 3 - The evolution of the re-epithelialization signs of infected wounds among rabbits: A, untreated (control); B, collagenase treated; and $\mathbf{C}$, treated with $\mathrm{AM}$ at $7,14,21$, and 28 days post-wound induction $\left({ }^{*} \mathrm{p}=0.05\right)$.

\section{Fibroplasia}

Organized fibrosis with more collagen fibers and fewer fibroblasts (which classified as moderate/severe) was not observed on Day 7 in any group. On Day 14, fibrosis was observed in three
(60\%) of Group A animals, five (100\%) Group B animals and three (75\%) Group C animals. On Day 21, fibrosis was present in three (60\%) Group A animals as well as five and four (100\%) of the animals in Groups B and C, respectively. On Day 28, fibrosis was observed in $100 \%$ of animals in Groups $A$ and $C(p=0.001)$ and $80 \%$ of the animals in Group B ( $p=0.006$; Table 4 and Figure 4).

TABLE 4 - Organized fibrosis signs of infected wounds among rabbits: A, untreated (control); B, collagenase-treated (control); and C, treated with $\mathrm{AM}$ at 7, 14, 21, and 28 days post-wound induction

\begin{tabular}{lccccccccc}
\hline \multirow{2}{*}{ GROUPS } & \multicolumn{1}{c}{ DAYS } \\
\cline { 2 - 10 } & \multicolumn{2}{c}{7} & \multicolumn{1}{c}{14} & \multicolumn{2}{c}{21} & \multicolumn{2}{c}{28} \\
\cline { 2 - 10 } & $\mathrm{n}$ & $\%$ & $\mathrm{n}$ & $\%$ & $\mathrm{n}$ & $\%$ & $\mathrm{n}$ & $\%$ \\
\hline A (control) & 0 & 0 & 3 & 60 & 3 & 60 & $5 \bullet$ & 100 \\
B (collagenase) & 0 & 0 & 5 & 100 & 5 & 100 & $4 *$ & 80 \\
C (AM) & 0 & 0 & 3 & 75 & 4 & 100 & $4 \bullet$ & 100 \\
\hline
\end{tabular}

*p $=0.006 ; \cdot \mathrm{p}=0,001$

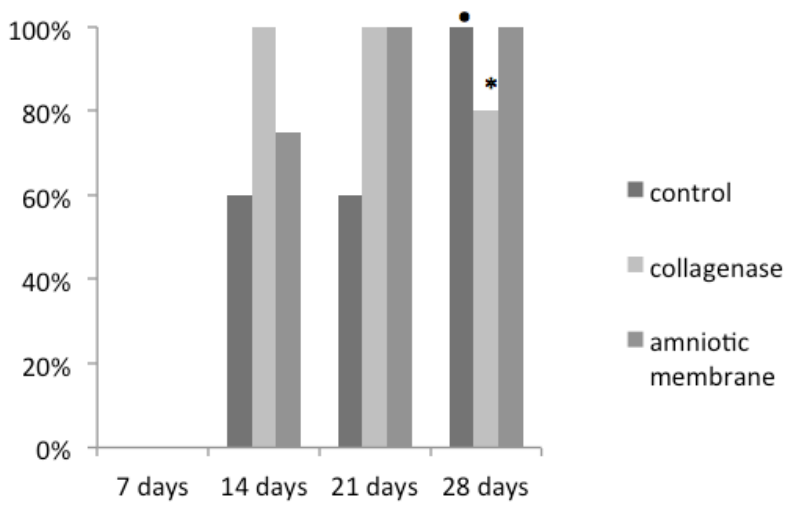

FIGURE 4 - The evolution of infected wound organized fibrosis among rabbits: A, untreated (control); $\mathbf{B}$, collagenase treated; and $\mathbf{C}$, treated with $\mathrm{AM}$ at $7,14,21$, and 28 days post-wound induction $\left({ }^{*} \mathrm{p}=0.006 \cdot \mathrm{p}=0.001\right)$.

\section{Discussion}

A wound is any loss of soft tissue continuity with or without local function loss. The body starts repairing this damage immediately after it occurs ${ }^{1-2}$. The current study tested a solution capable of affecting the angiogenesis, fibroplasia, and epithelialization of chronic wounds.

A dry wound was selected as a control group without medical interference (Group A). Collagenase treatment was selected as a second control group (Group B) because it is a widely used, easily accessible, and affordable medication.

$\mathrm{AM}$ (i.e., the amnion overlying the fetal placenta) is derived from the epiblast (i.e., fetal ectoderm) and attached to the corium where it can be easily separated using blunt dissection. Its 
histological structure develops from conception to birth, and it is resilient, smooth, shiny, flexible, and slender ${ }^{20-21}$. AM consists of five layers ${ }^{22-23}$, including an internal monolayer of non-adhesive cuboidal epithelial cells that are rich in immunomodulatory cytokines and epithelial growth factors. Hemidesmosomes connect this layer to the second, which is a thick and resistant basal layer formed primarily of type-IV collagen and laminin. The second layer adheres to a third thin layer of connective tissue that underlies the stromal matrix, which is completely avascular and divided into three additional layers: a compact layer of collagen, a layer of fibroblasts, and a spongy layer ${ }^{22-23}$. Compared with other bodily structures, smooth muscle, nerves, blood, and lymphatic vessels are absent ${ }^{5-6,23}$. The face implanted on the wound reflects AM's ability to act as a biological dressing: Its epithelial face functions as a biological support, whereas its stromal face acts as a graft $^{5,23}$.

The characteristics of AM such as antibacterial activity $^{5,13,19}$ that are likely due to elements such as interferon ${ }^{24}$, lysozyme, transferrin, progesterone ${ }^{24-26}, 7 \mathrm{~S}$ immunoglobulin, and $\mathrm{B} 1 \mathrm{c} / \mathrm{B} 1 \mathrm{a}$ globulin present in amniotic fluid ${ }^{20-21,23}$. Its low antigenicity is due to the absence of certain surface antigens on amniotic epithelialcells(HLAA, HLAB, HLAC, and HLAD) $)^{5,13,22-}$ 23,25-26, which promote faster epithelialization ${ }^{5,13,22-23,25-26}$ due to the numerous growth factors contained (e.g., EGF, KGF, HGF, FGF, TGF-alpha, TGF-beta1, and TGF-beta2) $)^{5,13,22-23 \text {, }}$ 25-26. AM also creates an anti-inflammatory action resulting from the large quantities of substances it contains that inhibit inflammatory mediators such as proteases ${ }^{5,13,22-23,25-26}$. AM also reduces the formation of retracted scar most likely by acting as a mechanical barrier against the formation of fibrosis ${ }^{26}$, thereby increasing the rate of inflammatory cell apoptosis and reducing the apoptosis of epithelial cells ${ }^{21,23,27}$. AM also reduces local exudates by adhering tightly to the wound ${ }^{23,26}$, while reducing the number of adhesions between neural and peritoneal structures ${ }^{5,15}$. Based on these properties, AM has been recommended as an in vitro substrate to cultivate various cell types ${ }^{8,16,18}$ furthermore, it has an apparent analgesic effect, thereby preventing nerve bundle exposure ${ }^{21,23,26}$.

This study used AM with its stromal face in contact with the open area of wounds, and the histology did not show evidence of an AM effect; however, whether it was eliminated, resorbed, or even removed from the animal could not be determined.

In Group A, lymphocytes and macrophages predominated between 14 and 28 days; this effect might have occurred due to the phagocytosis of the necrotic tissue and bacteria in these wounds. Significant differences were not observed between the collagenase and AM groups on Day 14, at which point mixed inflammatory infiltrate predominated. Mononuclear lymphocytes were the most predominant on Days 21 and 28. We have cannot explain this effect because we did not observe the decrease in the inflammatory infiltrate described in the literature. These results might be due to membrane reabsorption; however, the histology was unable to verify this process because we could not confirm whether phagocytized amorphous material was present inside the foreign-body giant cells. One might question why a decrease in the inflammatory process itself was not observed despite the decrease in the resolution time. The resolution time was faster in Group $\mathrm{C}$, which accentuated its decrease in inflammation beginning on Day 21 and remained discrete, whereas the process moderately persisted after this period in Groups A and B.

A humid environment facilitates cell migration, the formation of tissue granulation, and epithelialization. We believe that AM maintained a more humid environment by decreasing the loss of local exudate; thereby, explaining the moderate presence of granulation tissue during the early phase. However, this explanation suggests that collagenase, which also retains local moisture, should have a similar clinical picture. One might suppose that the increased moisture provided by collagenase increases its enzymatic action, thereby degrading the native collagen and causing necrosis. The increased presence of this healing promoting factor, concomitant with the formation of granulation tissue, might be responsible for the discrete formation of this tissue and its decreased expression from Days 21 to 28 in Group B.

In this study, organized fibrosis with more collagen fibers and fewer fibroblasts was observed in all the groups beginning on Day 14. This finding was not one of the proposed characteristics of AM (i.e., the reduction of scar retraction ${ }^{22-23}$,a process directly related to the quantity and organization of the collagen fibers present in the scar).

We believe that additional studies should evaluate the efficacy of this biological dressing on wounds with poor vascularization or in other environments that are not favorable to healing.

\section{Conclusions}

The use of amniotic membrane as a biological dressing for infected wounds did not significantly alter the inflammatory phase of healing. A significant increase in angiogenesis was observed during the granulation phase up to 14 days, but it did not significantly affect the epithelialization or fibrosis of the fibroplasia phase. 


\section{References}

1. Blanes L. Tratamento de feridas. In: Baptista-Silva JCC, editor. Cirurgia vascular: guia ilustrado. São Paulo: 2004. Disponível em http://www. bapbaptista.com

2. Broughton G 2end, Janis JE, Attinger CE. The basic science of wound healing. Plast Reconstr Surg. 2006;117(7 Suppl.):12S-34S.

3. R\&D Systems. Cytokines in wound healing. Mini Reviews 2010. Available from http://translate.googleusercontent.com/ translate_c?hl=pt-BR\&sl=en\&u=http://www.rnd

4. Mendonça RJ, Coutinho-Netto J. Aspectos celulares da cicatrização. An Bras Dermatol. 2009;84:257-62.

5. Fontenla JR, Vázquez X, Diaz P, Gatell J, Pita D. Membrana amniótica. Características, efectos y aplicaciones em oftalmologia. Viernes. 2003;64:53-68.

6. Takahiro N, Makato Y, Igby H, Fullwood NJ, Wakana I, Tsutomu I, Sotozono C, Nakamura T, Shimizu Y, Kinoshita S. Sterillized, Freezedried amniotic membrane: a usefull substrate for ocular surface reconstruction. Invest Ophthalmol Vis Sci. 2004;45 (1): 93-9.

7. Rita Singh, Chlouhan US, Purohit S, Gupta P, Kumar P, Kumar A, Chacharkar MP, Kachhawa D, Ghiya BC. Radiation processed amniotic membranes in the treatment of non-healing ulcers of different etiologies. Cell Tissue Bank. 2004;5:129-34.

8. Rita Singh, Chacharkar MP. Dried gamma-irradiated amniotic membrane as dressing in burn wound care. J Tissue Viability. 2011;20:49-54.

9. Carvalho BR, Reis RM, Moura MD, Lara LAS, Nogueira AA, Ferriani RA. Neovaginoplastia com membrana amniótica na síndrome de Mayer-RokitansKy-Küster-Hauser. Rev Bras Ginecol Obstet. 2007;29:619-24.

10. Fishman IJ, Flores FN, Brantley Scott F, Spjut HJ, Morrow B. Use of fresh placental membranes for bladder reconstruction. J Urol. 1987; 138:1291-4.

11. Mitsuhiro H, Hironori F, Yutaka H, Junkoh Y. Autologous amnion graft for repair of myelomeningocele: technical note and clinical implication. J Clin Neurosci. 2004;11:408-11.

12. Kesting MR, Loeffelbein DJ, Classen M, Slotta-Huspenina J, Hasler RJ, Jacobsen F, Kreutzer K, Al-Benna S, Wolff KD, Steinstraesser L. Repair of oronasal fistulas with human amniotic membrane in minipigs. Br J Oral Maxillofac Surg. 2010;48:131-5.

13. Kim H, Son D, Choi TH, Jung S, Kwon S, Kim J, Han K. Evaluation of an amniotic membrane-collagen dermal substitute in the management of full thickness skin defects in a pig. Arch Plast Surg. 2013;40:11-8.

14. Meller D, Pauklin M, Thomasen H, Westekemper H, Steuhl KP. Amniotic membrane transplantation in the human eye. Dtsch Arztebl Int. 2011;108:243-8.

15. Özeren S, Çorackci A, Erk A, Yücesoy G, Yücesoy I, Karabacak O. The effects of human membrane and fibrin sealant in the prevention of postoperative adhesion formation in the rabbit ovary model. J Obstet Gynaecol. 1998;389:207-9.

16. Covre JL, Loureiro RR, Cristovam PC, Silva RJR, Haapalainen EF, Gomes JAP. Comparação entre membrana amniótica com e sem epitélio como substrato para cultura de células epiteliais do limbo ex vivo. Arq Bras Oftalmol. 2011;74:114-7.

17. Paracchini V, Carbone A, Colombo F, Castellani S, Mazzucchelii S, Gioia SD, Degiorgio D, Seia M, Porretti L, Colombo C, Conese M. Amniotic mesenchymal stem cells: a new source for hepatocytelike cells and induction of CFTR expression by coculture with cystic fibrosis airway epithelial cells. J Biomed Biotechnol. 2012;2012:575471.
18. Jingbo L, Hosam S, Yao F, Giegengack M, Scheffer CG Tseng. Oral mucosal graft with amniotic membrane transplantation for total limbal sten cell deficiency. Am J Ophthalmol. 2011;152:739-47.

19. Díaz-Prado S, Muiños-López E, Hermida-Gómes T, Cicione C, Rendal-Vásquez ME, Fuentes-Boquete I, de Toro FJ, Blanco FJ. Human amniotic membrane as an alternative source of stem cells for regenerative medicine. Differentiation. 2011;81(3):162-71.

20. Dua HS. Amniotic membrane transplantation. Br J Ophthalmol. 1999;83:748-52.

21. Del Campo Z, Gris O. Aplicaciones de la membrane amniótica en patologia ocular. Ann Oftalmol. 2002;10:128-41.

22. Ninknejad H, Paeini-Vayghan G, Tehrani FA, Khayat-Khoeri M, Peirovi H. Side dependent effects of human amnion on angiogenesis. Placenta. 2013;34:340-5.

23. Matthews RN, Faulk WP, Bennett JP. A review of the role of amniotic membranes in surgical practice. Obstet Gynecol Annu. 1982;11:31-58.

24. Franco GR, Carvalho AF, Kroon EG, Lovage S, Werenne J, Golgher RR, Ferreira PC, Bonjardim CA. Biological activities of human amniotic membrane interferon. Placenta. 1999;20:189-96.

25. Loeffelbein DJ, Baumann C, Stoeckelhuber M, Hasler R, Mücke T, Steinsträber L, Drecoll E, Wolff KD, Kesting MR. Amniotic membrane as part of skin substitute for full thickness wounds: an experimental evaluation in a porcine model. J Biomed Mater Res B Appl Biomater. 2012;100(5):1245-56.

26. Gomes MF, Santos VW, Nogueira NO. Membrana amniótica liofilizada sobre feridas cruentas em áreas de biópsia bucal. Rev Assoc Paul Cir Dent. 2001;55:327-31.

27. Ting L, Yanyuan X, Yanling D, Yajie S, Xinjie Z, Jing ZA Amniotic membrane traps and induces apoptosis of inflammatory cells in ocular chemical burn. Mol Vis. 2012;18:2137-46.

\section{Correspondence:}

Ivana Duval-Araujo

Departamento de Cirurgia

Avenida Professor Alfredo Balena 190

30130-100 Belo Horizonte - MG Brasil

idaraujo@medicina.ufmg.br

Received: Dec 18, 2013

Review: Feb 20, 2014

Accepted: March 19, 2014

Conflict of interest: none

Financial source: none

${ }^{1}$ Research performed at Medical School, Federal University of Minas Gerais (UFMG), Belo Horizonte-MG, Brazil. Part do Master degree thesis, Postgraduate Program in Surgery. Tutor: Ivana Duval de Araújo. 